\title{
Sobre as experiências relativas à imantação do ferro e do aço pela ação da corrente voltaica: uma tradução comentada do artigo escrito por François Arago (On the experiences concerned with the magnetization of iron and of steel by the action of the voltaic current: a commented Portuguese translation of the article written by François Arago)
}

\author{
Moacir Pereira de Souza Filho ${ }^{1,2}$ e João José Caluzi ${ }^{1,2}$ \\ ${ }^{1}$ Programa de Pós-Graduação em Educação para Ciência, Faculdade de Ciências, \\ Universidade Estadual Paulista, Bauru, SP, Brasil \\ ${ }^{2}$ Departamento de Física, Faculdade de Ciências, Universidade Estadual Paulista, Bauru, SP, Brasil \\ Recebido em 28/3/2008; Revisado em 15/11/2009; Aceito em 24/1/2009; Publicado em 30/4/2009
}

O objetivo deste trabalho é divulgar, por meio de uma tradução comentada, um dos principais trabalhos escritos por Dominique François Jean Arago (1786-1853) relativo ao eletromagnetismo. Trata-se de uma descrição das experiências feitas por ele, relativas à magnetização do ferro e do aço pela ação da corrente voltaica.

Palavras-chave: François Arago, André-Marie Ampère, eletromagnetismo.

The goal of this paper is to divulge, through a commented Portuguese translation, an important work written by Dominique François Jean Arago (1786-1853) concerned with electromagnetism. He gives an account about experiments related to the magnetization of iron and of steel by the action of the voltaic current.

Keywords: François Arago, André-Marie Ampère, electromagnetism.

\section{Introdução}

A eletricidade e o magnetismo, por um longo período, foram considerados ramos de estudos distintos. Contudo, havia algumas evidências que indicavam a possibilidade de interação entre os fenômenos elétricos e magnéticos. Benjamin Franklin (1706-1790) relatou que agulhas de bússolas, ao serem atingidas pelo fogo elétrico (faíscas elétricas), perdiam suas propriedades magnéticas. Ele relatou também que agulhas de costura, ao serem percorridas pela eletricidade proveniente de garrafas de Leiden, 1 adquiriam tais propriedades se alinhando ao campo magnético terrestre quando postas para flutuar em um recipiente contendo água $^{2}$ [1]. Além destas observações pontuais entre os fenômenos elétricos e magnéticos, buscavam-se outras equivalências mais profundas entre os mais diversos fenômenos da natureza, devido à influência da Naturphilosophie $e^{3}$ no período. Para uma discussão mais aprofundada sobre o tema, ver Ref. [3]. Outro exemplo da busca da equivalência e similaridade entre eletricidade e magnetismo, pode ser encontrado no artigo "Sobre os experimentos eletromagnéticos dos Srs. Ørsted e Ampère" [4], publicado em 1821, por Jean Nicolas Pierre Hachette (1769-1834). Neste trabalho, Hachette comenta o experimento realizado por ele e pelo físico e químico francês Charles Bernard Desormes (17771862). Em 1805, puseram uma bateria elétrica sobre um pequeno bote e colocaram ambos para flutuarem

\footnotetext{
${ }^{1}$ E-mail: moacir@fc.unesp.br.

${ }^{1}$ Dispositivo utilizado na época, análogo ao capacitor, cuja função básica era armazenar a eletricidade gerada por atrito para ser posteriormente utilizada.

"Franklin relatou a influência exercida pelo "fogo elétrico" sobre as agulhas imantadas das bússolas do navio do capitão Waddel. Segundo ele, as "bússolas perderam a virtude da magnetita ou, os polos foram invertidos, o ponto norte girando ao sul". Ele também escreve ao amigo Peter Collinson: "Pela eletricidade nós freqüentemente temos dado aqui [na Filadélfia] polaridades às agulhas, e as invertido com facilidade. Sr. Wilson tentou com uma força muito pequena. Uma descarga de quatro jarras de vidro (garrafas de Leiden) grandes, enviadas a uma fina agulha de costura, dá a ela polaridade e, ela se alinhará quando posta [para flutuar] sobre a água" [1, p. 289].

${ }^{3}$ Trata-se de uma corrente de pensamento germânica que advogava à unidade entre as diferentes ciências que compõe o saber. Esta concepção metafísica concebia que os fenômenos naturais como luz, calor, eletricidade e magnetismo eram produzidos pelo mesmo poder original. Para mais detalhes ver Ref. [2].
} 
em água, na tentativa de verificar se a Terra possuía polos elétricos, assim como, ela possui o meridiano magnético.

O trabalho de Hans Christian Ørsted ${ }^{5}$ (1777-1851), em 1820, apresenta uma relação mais sólida entre os fenômenos elétricos e magnéticos, dando início ao eletromagnetismo. ${ }^{6}$ Dominique François Jean Arago (1786-1853) assiste em Genebra a repetição do experimento feito por Ørsted. De volta a Paris, ele publica nos Anais de Química e Física ${ }^{7}$ uma tradução deste trabalho. Comunica à Academia de Ciências de Paris, $\frac{8}{8}$ em 4 de setembro de 1820, a nova descoberta e repete este experimento perante a Academia em 11 de setembro do mesmo ano [5]. A partir daí, muitos cientistas como André-Marie Ampère ${ }^{9}$ (1775-1836), Jean Baptiste Biot (1774-1862), Felix Savart (1791-1841) entre outros, trabalhavam experimentalmente e teoricamente sobre o tema, em busca de um modelo para descrever o fenômeno da interação entre o fio condutor e a agulha imantada da bússola.

Em 25 de setembro de 1820, Ampère leu seu primeiro trabalho sobre os fenômenos eletrodinâmicos para a Academia de Ciências e, em 2 de outubro do mesmo ano, ele apresentou seu trabalho por escrito. Nele, descreve suas observações da ação entre correntes e defende a concepção da ação à distância entre os corpos interagentes, ao conceber a existência de correntes elétricas no interior da agulha imantada. Para ele, a corrente elétrica que circulava pelo fio interagia, pelo princípio newtoniano da ação e reação, com aquelas existentes no interior da agulha da bússola. Portanto, ele reduziu o experimento de Ørsted à interação entre correntes elétricas [7]. Uma tradução da primeira parte deste trabalho para o português encontra-se na Ref. [8].

Para testar suas idéias Ampère, enrolou o fio na forma de uma espiral plana e demonstrou que o fenômeno da atração e repulsão podia ser observado fazendo passar uma corrente elétrica constante através do condutor e aproximando da espira um ímã em forma de barra. Ao substituir o ímã por outra espiral, alinhada com a primeira, ele notou que também era possível observar os fenômenos atrativos e repulsivos por meio da interação entre espirais, conduzindo correntes constantes.
A atração ou repulsão depende do sentido no qual os fios são enrolados e, do sentido com que as correntes elétricas circulam pelas espiras. Este foi o primeiro experimento feito por Ampère para demonstrar a interação entre correntes elétricas [9]. Pode-se facilmente demonstrar seus efeitos por meio de uma montagem didática simples, proposta em [10]. Uma versão para a língua inglesa desta sugestão experimental didática pode ser encontrada na Ref. [11].

Contrariamente a esta concepção, Biot e Savart [12] apresentam um trabalho à Academia de Ciências de Paris, em 30 de outubro de 1820, em que eles interpretam a experiência de Ørsted, por meio da interação entre polos magnéticos. Segundo eles, a corrente elétrica, ao passar pelo circuito, magnetizaria o fio condutor. Consequentemente, os polos magnéticos, espalhados ao longo da seção reta do fio, interagiam com os polos magnéticos ou "moléculas" magnéticas da agulha imantada da bússola. Este artigo encontra-se traduzido para o português em [13].

François Arago, adepto da concepção de Ampère, publica também no ano de 1820, nos Anais de Química e de Física, ${ }^{10}$ um trabalho intitulado Experiências relativas à imantação do ferro e do aço pela ação da corrente voltaica ${ }^{11}$ [14]. Tendo em vista a importância deste trabalho, apresentaremos aqui, sua tradução comentada.

Neste artigo, Arago observa que um fio ligado à bateria voltaica é capaz de atrair pequenas limalhas de ferro ao seu redor. Ao enrolar o fio no formato de uma espira, ele observa a presença de polaridades em suas extremidades. A posição destes polos depende do sentido da corrente e do sentido em que o fio é enrolado. Colocando-se um núcleo de aço no interior das espiras o efeito se intensifica e o aço adquire propriedades magnéticas. Finalmente, Arago se preocupa em diferenciar este tipo de imantação daquele em que a descarga elétrica percorre a agulha de aço longitudinalmente, o que já havia sido tentado, em vão, por alguns cientistas do século XVIII. Este trabalho merece destaque não só pela sua simplicidade e clareza, mas principalmente, pela sua relevância. Na época, este trabalho mostrou que, por meio da eletricidade, era possível obter efeitos

\footnotetext{
${ }^{4}$ Segundo Hachette, "Ritter [Johan Wihelm Ritter (1776-1810)] concluiu (Journal de Physique, t 57, ano 1803) a partir de alguns experimentos, que até agora não foram verificados que a Terra tem polos elétricos, como ela tem o meridiano magnético. Sr. Desormes e eu tentamos, em 1805, determinar a direção que uma pilha horizontal adquiria [...]. Nós colocamos esta pilha sobre um [pequeno] bote, que flutuou na água de um [grande] tonel. Nós sabíamos que uma barra de aço magnetizada, com peso aproximadamente igual ao da pilha, quando colocado sobre o bote, giraria, depois de algumas oscilações, em direção ao meridiano magnético. A pilha, colocada na mesma situação não adquiriu nenhuma direção determinada" [4, p. 43].

${ }^{5}$ Hans Christian Ørsted (1777-1851) cientista dinamarquês, professor da Universidade de Copenhagen e Secretário Vitalício da Academia de Ciências de Copenhagen [5].

${ }^{6}$ Em 1820, Ørsted mostrou a interação entre os fenômenos elétricos e magnéticos. Ao fazer circular uma corrente elétrica através de um circuito fechado, ele mostrou que a corrente provoca um torque na agulha imantada de uma bússola colocada nas proximidades do fio condutor, posicionando-a praticamente perpendicular a este fio [6].

${ }^{7}$ Annales de Chimie et Physique.

${ }^{8}$ Académie des Sciences de Paris.

${ }^{9}$ André-Marie Ampère (1775-1836), matemático, físico e químico francês. Interpretou a experiência de Ørsted como a interação entre correntes elétricas, pois para ele a estrutura interna de um ímã era composta por correntes elétricas circulares microscópicas.

${ }^{10}$ Annales de chimie et de physique, v. 15, p. 93. Disponível em: http://www.ampere.cnrs.fr

${ }^{11}$ Expériences relatives a l'aimantation Du fer et Du l'acier par l'action Du courant voltä̈que.
} 
magnéticos semelhantes a um ímã comum em forma de barra. Ou seja, o fio enrolado em hélice apresenta polaridades e produz efeitos atrativos e repulsivos.

Todas as notas deste artigo são dos tradutores, exceto a nota 46 que é do próprio Arago. As palavras entre colchetes e as figuras foram introduzidas com o objetivo de facilitar o entendimento do texto.

\section{Dados biográficos de François Arago}

Dominique François Jean Arago, físico francês, nasceu em 26 de fevereiro de 1786 em Estagel, um pequeno vilarejo próximo a Perpignan e, morreu em Paris, em 2 de outubro de 1853 [15, p. 324]. Mostrando-se decidido a ingressar na carreira militar, Arago entrou no Colégio de Perpignan, onde iniciou seus estudos relacionados à matemática na sua preparação para o exame de ingresso à renomada Escola Politécnica de Paris, com o objetivo de tornar-se oficial engenheiro. Em 1803, entrou para a Escola Politécnica, mas seus estudos não o conduziram ao seu objetivo original [16, p. 160]. No ano seguinte, começou a fazer pesquisas sobre astronomia no Observatório de Paris. Pierre Simon de Laplace (1749-1827), que liderava o Observatório e o Bureau des Longitudes, recrutava jovens pesquisadores formados na Escola Politécnica para pesquisas de seu interesse [17, p. 46]. Em 1806, Arago foi nomeado secretário do Bureau des Longitudes e enviado à Espanha, junto com Biot, para uma expedição geodésica ${ }^{12}$ [16, p. 160]. Sua operação foi interrompida pela guerra entre França e Espanha. Em junho de 1808, foi aprisionado, mas logo, escapou e, após várias aventuras, ele finalmente retornou à França [15, p. 324]. De volta a Paris, em 1809, Arago passou a fazer parte das principais instituições da França. Com apenas vinte e três anos de idade, sucedeu a Jérôme Lalande (1732-1807) e foi eleito membro da Academia de Ciências de Paris [18, p. 18]; foi indicado para assumir a cadeira de geometria analítica da Escola Politécnica e, também; foi nomeado astrônomo do Observatório de Paris. Em 1825, Arago foi o primeiro cientista francês a receber uma medalha de honra da Royal Society de Londres [16, p. 160]. Após a morte de Laplace, o prestígio de Arago cresceu; ele foi eleito secretário permanente da Academia de Ciências e, quatro anos mais tarde, tornou-se diretor do Observatório de Paris [17, p. 47]. Arago foi um ardente político liberal e fez parte das revoluções de 1830 e 1848, quando desenvolveu um importante papel político. Após a segunda revolução, ele se tornou Ministro de Guerra e da Marinha [15, p. 324].

Os trabalhos científicos de Arago estão relacionados principalmente com o eletromagnetismo e com a teoria ondulatória da luz, ver Refs. [14, 15, 18, 19]. "Continuando o trabalho de H. C. Ørsted, Arago mostrou, em 1820, que uma espira cilíndrica feita de fio de cobre, por meio da qual flui uma corrente elétrica, atrai limalhas de ferro assim como um ímã comum, mas que as limalhas se desprendem assim que a corrente cessa"13 [20]. Ver a Ref. [14]. "Arago também mostrou, em 1824, que um disco de cobre produz a oscilação em uma agulha magnética suspensa sobre ele, relatando verbalmente à Academia de Ciências, os resultados de alguns experimentos que ele fez, sobre a influência que metais exercem sobre a agulha magnética" [20]. Ver a Ref. [18]. A presença do disco de cobre diminui rapidamente a amplitude de oscilação da agulha magnética, sem alterar sensivelmente o seu período. Ou seja, se uma agulha magnética oscilar próximo a um disco de cobre, sua amplitude de oscilação diminui. Segundo Arago, o movimento é relativo, pois se a agulha magnética estiver parada e o disco de cobre se mover, depois de algum tempo, a agulha entra em oscilaçãd ${ }^{14}[18$, 19]. "Estes efeitos foram posteriormente explicados por Michael Faraday ${ }^{15}$ (1791-1867) como sendo devidos ao fenômeno da indução de correntes elétricas"

Os trabalhos de Arago relacionados à óptica foram extremamente relevantes para o progresso da teoria ondulatória da luz. ${ }^{17}$ Ao tentar interpretar o fenômeno da

\footnotetext{
${ }^{12}$ Arago e Biot foram incumbidos da determinação do comprimento do arco do meridiano.

${ }^{13}$ Trabalho que abordaremos com detalhes neste artigo.

14 "Em seus recentes experimentos o Sr. Arago mostrou que uma placa de cobre, ou alguma outra substância, sólida ou líquida, colocada abaixo de uma agulha magnética, exerce sobre esta agulha uma ação, a qual, o efeito imediato é diminuir o arco de vibração da agulha, sem alterar sensivelmente seu tempo de vibração. O fenômeno que ele comunica agora à Academia é, por assim dizer, o inverso do precedente. Desde que uma agulha em movimento é colocada em repouso por uma placa que está parada, o Sr. Arago pensou que se uma placa de cobre, por exemplo, for movida, com uma determinada velocidade, debaixo de uma agulha magnética cercando-a, neste caso, ao redor por todos os lados, a agulha não se posiciona mais em sua posição normal; ela repousa em uma posição diferente do meridiano magnético; e tão mais distante do plano do meridiano, quanto mais rápido for o movimento de rotação. Se o movimento de rotação da placa for suficientemente rápido, a agulha, embora bastante distante da placa, também gira continuamente ao redor do seu ponto ou seu centro de suspensão" [17, p. 291].

15 "Parece-me que existem muitas pesquisas que ainda deveriam ser empreendidas no caminho no qual eu iniciei, apesar da explicação aparentemente satisfatória que Faraday deu, de uma parte do fenômeno que eu descobri" [18, p. 290].

${ }^{16}$ Arago havia demonstrado que quando uma placa de metal se move nas vizinhanças de um ímã, ela sofre influência dele e tem o seu movimento alterado. Faraday explicou este fenômeno pela lei que governa a evolução da eletricidade pela indução eletromagnética, sugerindo que correntes elétricas são produzidas no metal, e que, o movimento do metal depende da interação destas correntes com a resultante das linhas de força magnética [21, p. 34].

${ }^{17} \mathrm{O}$ modelo corpuscular newtoniano, devido a sua capacidade de interpretar corretamente vários fenômenos luminosos, afirmou-se como a concepção hegemônica nos séculos XVII e XVIII, relegando pouco espaço as pesquisas fundamentadas na visão ondulatória de Huygens [22, p. 158].

${ }^{18}$ Os resultados das observações feitas por Bradley, em 1725, corroboraram a hipótese de que a luz levava um tempo finito para atingir a superfície da Terra, vindo das estrelas. Em um experimento realizado em 1729, ao medir o fenômeno de paralaxe astronômica
} 
aberração das estrelas fixas observado por Bradley, 18 Arago e Biot verificaram em 1806, por meio da medida da refração da luz emitida por vários corpos celestes, a constância da velocidade da luz, o que não era aceito pela teoria corpuscular. ${ }^{19}$ Em 1810, ${ }^{20}$ Arago verificou que a composição entre a velocidade da luz produzida pela adição/subtração com a velocidade de translação da Terra, não mostrou variação no ângulo de refração em um prisma posicionado na Terra. Essas experiências revelaram um elo fraco na teoria corpuscular, dando oportunidade para que Fresnel interpretasse os fenômenos da luz, considerando-se a influência do movimento dos corpos, dentro de uma visão ondulatória da luz. Fresnel supôs que uma pequena parte deste éter era arrastada por corpos transparentes em movimento com a Terra. ${ }^{21}$ Neste caso, os dois fenômenos podiam ser interpretados pela teoria ondulatória (Refs. [17, 22]).

Arago e Fresnel publicaram vários trabalhos relacionados a natureza da luz. Em um trabalho importante, eles descrevem os experimentos sobre a interferência da luz polarizada, no qual, pode-se concluir que as vibrações da luz são transversais à sua linha de propagação [15].

\section{Considerações finais}

Durante muito tempo se buscou a interação entre os fenômenos elétricos e magnéticos, fazendo com que, descargas elétricas percorressem agulhas de aço longitudinalmente, mas os experimentos realizados não apresentaram resultados conclusivos. Somente em 1820, com experimento de Ørsted, pôde-se verificar a interação entre estes fenômenos, dando início ao eletromagnetismo. Ele mostrou que a corrente elétrica que passa pelo fio condutor interage com a agulha imantada da bússola (princípio do motor elétrico). Posteriormente, Ampère mostrou que a interação eletrodinâmica de fios conduzindo correntes constantes, interagiam entre si, apresentando efeitos atrativos e repulsivos, semelhante aos ímãs. A grande contribuição de Arago para o eletromagnetismo foi mostrar que, além da interação entre estes fenômenos, era possível gerar um fenômeno a partir do outro. O artigo de Arago, que vamos expor neste trabalho, mostrou que a corrente que flui através de um solenóide é capaz de imantar um cilindro de aço (eletroímã), que inicialmente, estava totalmente desprovido das características magnéticas. Isto foi extremamente relevante, pois a partir daí, seria possível obter imãs artificiais por meio da eletricidade. Arago também mostrou que metais sofrem interação ao se moverem $^{22}$ próximos aos ímãs, o que, de acordo com Faraday, era devido às correntes elétricas induzidas pelos ímãs nos metais.

A contribuição de Faraday foi imaginar a existência de linhas físicas de força no entorno dos ímãs ou dos solenóides. Estas linhas podiam ser visualizadas espalhando limalhas de ferro em suas proximidades e, observando que cada limalha se posicionava, de modo a formar linhas retilíneas ou curvilíneas, o que hoje em dia, concebemos como sendo, as linhas de campo magnético. Baseado nisto, ele mostrou experimentalmente o poder que, ímãs ou correntes elétricas, variando no tempo, possuem em produzir alguns efeitos em sua vizinhança imediata. Ele mostrou que, se movermos um ímã próximo a um enrolamento de fio condutor (semelhante a um solenóide), ligado a um galvanômetro, poderemos observar, por meio do movimento de seu ponteiro, a presença de correntes elétricas induzidas. Portanto, Faraday mostrou que, por meio do magnetismo, era possível gerar a eletricidade (princípio do gerador elétrico). Ele também mostrou que, se tivermos dois enrolamentos próximos entre si, montados sobre um núcleo de ferro e, fizermos variar uma corrente no circuito primário, teremos uma corrente induzida no circuito secundário (transformador elétrico). Finalmente, mais tarde, James Clerk Maxwell (18311879) sintetizou o eletromagnetismo por meio de algumas expressões matemáticas e sugeriu que ondas eletromagnéticas podiam-se propagar pelo espaço na velocidade da luz (ondas de rádio e TV, microondas, etc.) e, que, a luz nada mais é, que uma onda eletromagnética.

Queremos destacar aqui que, os trabalhos destes cientistas foram fundamentais para a formação e a consolidação do eletromagnetismo, e que, especialmente os princípios físicos do trabalho de Arago, que vamos apresentar ao leitor, são utilizados em nosso cotidiano nos mais variados dispositivos eletro-eletrônicos, tais como, relês, talhas eletromagnéticas, válvulas solenóides, etc., com uma infinidade de aplicações práticas.

\section{Tradução}

\section{Sobre as experiências relativas à imantação do ferro e do aço pela ação da corrente voltaica [p. 93]}

A brilhante descoberta que o Sr. Ørsted acaba de fazer, consiste, como se tem visto,

\footnotetext{
das estrelas fixas, Bradley percebeu uma pequena variação na posição da estrela Gama, da constelação de Dragão. Segundo ele, este fenômeno era causado pela composição do movimento da luz com o movimento de translação da Terra [22, p. 158].

${ }^{19} \mathrm{Na}$ visão newtoniana, a velocidade de propagação dos corpúsculos de luz no espaço deveria depender das dimensões e distância dos corpos emissores [22, p. 162].

${ }^{20}$ Para mais detalhes a respeito do experimento de Arago de 1810, sobre o primeiro resultado experimental contra a existência do éter, ver Ref. [23].

${ }^{21}$ Esta proposição ficou conhecida como "hipótese de arrastamento parcial do éter luminoso" [22].

${ }^{22}$ Uma contribuição relevante de Arago foi estabelecer que o movimento é um elemento crucial na relação entre a eletricidade e o magnetismo.
} 
na ação que a corrente voltaica exerce sobre uma agulha de aço previamente imantada. Ao repetir as experiências do físico dinamarquês, reconheci que esta mesma corrente desenvolve fortemente a virtude magnética nas lâminas de ferro ou de aço, que inicialmente, estavam totalmente desprovidas [desta virtude]..$^{23}$

[p. 94]

Relatarei as experiências que estabelecem este resultado, na ordem, mais ou menos, em que elas foram feitas.

Tendo adaptado um fio cilíndrico de cobre, bem fino, a um dos polos da pilha voltaica,, 24 observei que no instante em que este fio estava em comunicaçãc $\frac{25}{25}$ com o polo oposto, ele atraía limalha de ferro doce, como teria feito um verdadeiro ímã.

O fio, mergulhado em limalhas, ${ }^{26}$ se carregava igualmente em todo o [seu] redor, ${ }^{27}$ e adquiria, por esta adição, um diâmetro quase igual aquele de um tubo [recoberto] de pluma comum.

Assim que o fio conjuntivo ${ }^{28}$ cessava de estar em comunicação com os dois polos da pilha ao mesmo tempo, as limalhas se desprendiam do fio e caíam.

Estes efeitos não dependem de uma imantação prévia das limalhas, visto que as barras ${ }^{29}$ de ferro doce ou de aço não atraíam nenhuma quantidade [de limalhas].

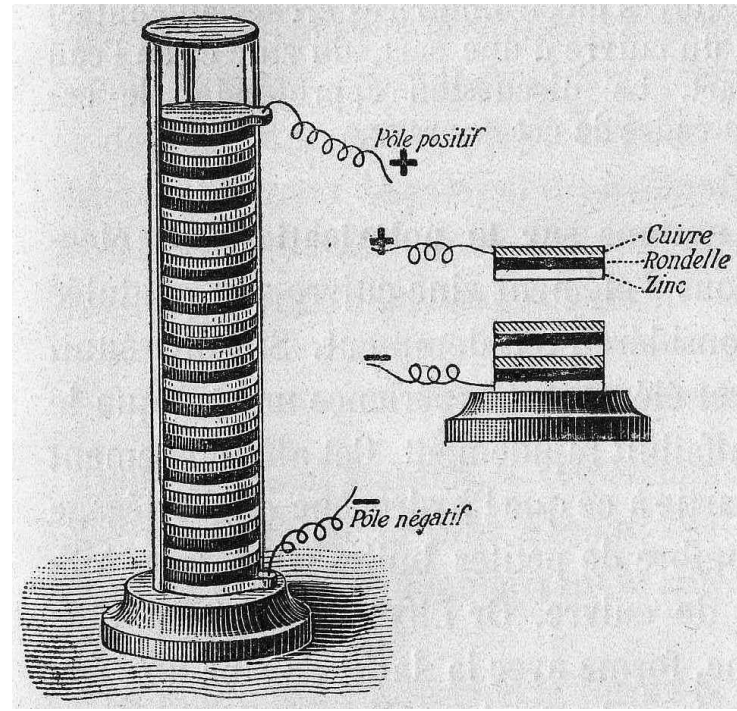

Figura 1 - Bateria elétrica construída por Alessandro Volta. Fonte: http://www.ieee.org/portal/cms_docs_iportals/ iportals/aboutus/history_center/milestones/volta.jpg

[Como] poderíamos explicar resumidamente [estas atrações] atribuindo a elas ações elétricas comuns,,$\sqrt[30]{ }$ se, ao repetir a experiência com limalhas de cobre e de latão, ou com serragens de madeira, observa-se que elas não atraem, em nenhum dos casos, de maneira perceptível ao fio conjuntivo.

Esta atração, que o fio conjuntivo exerce sobre as limalhas de ferro, diminui muito rapidamente à medida que a ação da pilha se enfraquece. Talvez a gente encontre, um dia, nos pesos da quantidade de limalhas, levantadas por um dado comprimento de fio, a medida da energia deste instrumento, 31 em diferentes épocas de uma mesma ex-

\footnotetext{
${ }^{23}$ Enquanto no experimento de Ørsted, a corrente elétrica atua sobre uma agulha imantada, Arago esclarece que, a ação da corrente no caso do seu experimento, ocorre em materiais magnetizáveis, porém não magnéticos.

${ }^{24}$ Alessandro Volta (1725-1827) havia recentemente proposto a construção de uma pilha voltaica ou bateria elétrica. "Este novo aparelho se assemelhava às antigas garrafas de Leiden, porém sua principal característica era a de fornecer uma carga ilimitada ou impor uma ação perpétua ao fluido elétrico, sendo que sua carga era restabelecida após cada descarga. A bateria voltaica era composta por discos metálicos de cobre, latão ou prata (semelhantes a moedas) e igual número de discos de estanho ou zinco (aproximadamente da mesma forma e tamanho) intercalados por discos de papelão, couro ou outro material absorvente umedecidos em salmoura ou solução ácida". Volta coloca sobre a mesa, por exemplo, "um disco de prata, colocando sobre ele um disco de zinco; sobre este segundo disco ele coloca um disco umedecido; então, novamente um disco de prata, um disco de zinco e entre os pares, novamente outro disco umedecido e assim sucessivamente. Por meio destes passos, forma-se uma coluna tão alta quanto possível, sem que ela caia" [24] (ver Fig. 1).

${ }^{25}$ No decorrer deste trabalho Arago utiliza a expressão estar em comunicação como sinônimo de estar em contato.

${ }^{26}$ Embora Arago utilize este termo no singular, optamos por utilizá-lo no plural no decorrer da tradução.

${ }^{27}$ Esta observação de Arago é relevante, uma vez que na época, Ørsted já defendia a existência de dois turbilhões em sentidos contrários girando ao redor do fio e, empurrando os polos da agulha da bússola em seu sentido radial [6]. Atualmente, considera-se a existência de um campo magnético nas adjacências de um fio condutor, conduzindo corrente elétrica.

${ }^{28}$ Naquela época utilizava-se o termo fio conjuntivo para expressar aquilo que atualmente denominamos de fio condutor.

${ }^{29}$ Arago utiliza a palavra fio para duas situações distintas as quais iremos diferenciá-las: Ele denomina fio conjuntivo para denominar o fio condutor de eletricidade. Outras vezes, ele também utiliza a palavra fio para designar agulha, cilindro, barra ou núcleo de aço ou de ferro doce que se coloca no interior das espiras. Traduziremos a palavra fio que aparece no decorrer do texto original pelo termo que julgarmos mais conveniente, a fim de tornar a leitura mais compreensível.

${ }^{30} \mathrm{~A}$ atração eletrostática age sobre diversos materiais, enquanto a atração magnética age apenas sobre objetos magnetizáveis.

${ }^{31}$ Arago sugeriu que, de alguma forma, seria possível verificar a energia de uma pilha. Certamente, Arago ainda não tinha claro que o princípio deste experimento estaria relacionado ao funcionamento de um voltímetro analógico. Ao conectar um voltímetro analógico aos terminais de uma pilha ou bateria, uma corrente elétrica passa pelo fio de uma bobina acoplada ao ponteiro de um galvanômetro. A corrente elétrica interage com um campo magnético de um ímã permanente, o que faz com que o ponteiro se desloque proporcionalmente a tensão elétrica medida.
} 
periência.

A ação do fio condutor sobre o ferro se exerce a distância. ${ }^{32}$ é fácil de notar, com efeito, que as limalhas

[p. 95]

se levantam bem antes do fio estar em contato com elas.

Eu não tenho falado até aqui apenas de um fio conjuntivo de latão; mas [também] fios de prata, de platina, etc. dão resultados análogos. Resta, entretanto, estudar se fios de mesma forma, massa ou diâmetro, de diferentes metais, agem exatamente com a mesma intensidade. 33

O fio conjuntivo somente comunica ao ferro doce uma imantação momentânea, se pequenos pedaços de aço forem usados, eles às vezes, se tornam permanentemente magnetizados. Eu mesmo cheguei a imantar, desta maneira, completamente, uma agulha de costura.

$\mathrm{O}$ Sr. Ampère, a quem eu mostrei estas experiências, acabava de fazer a importante descoberta que dois fios retilíneos e paralelos, através dos quais passam duas correntes elétricas, se atraem quando as correntes se movem no mesmo sentido, e se repelem quando elas são dirigidas em sentidos

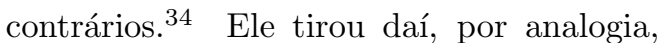
esta consequência que as propriedades atrativas e repulsivas dos ímãs dependem de correntes elétricas que circulam em torno das moléculas do ferro e do aço, em uma direção perpendicular à linha que une os dois polos. ${ }^{35} \mathrm{O}$ Sr. Ampère supôs ainda que, sobre uma agulha horizontal dirigida ao norte, a corrente na parte superior se move de oeste a leste. ${ }^{36}$ Estas visões teóricas lhe sugeriram, no mesmo instante, pensar que obteríamos uma melhor imantação ao substituir um fio condutor reto que eu tinha utilizado, por um fio enrolado em hélice, no centro do qual, a agulha de aço seria colocada. ${ }^{37}$ Ele esperava ainda que se obtivesse assim, uma posição constante dos polos, o que não se chegava

[p. 96]

pelo meu método 38 Eis como nós, o Sr. Ampère e eu, temos submetido estas conjecturas à prova da experiência.

Um fio de cobre enrolado em hélice [foi confeccionado, de modo que, as suas extremidades] fossem terminadas por duas porções retilíneas que podiam se adaptar, à vontade, aos polos opostos de uma forte pilha

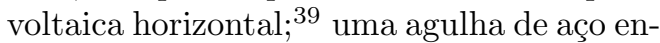
volvida em papel foi introduzida na hélice,

${ }^{32}$ Existem três tipos de interação entre corpos que obedecem à ação a distância. A força gravitacional, a força elétrica e a força magnética, que atuam com o inverso do quadrado da distância entre os corpos inter-agentes. Este tipo de ação desconsidera a existência de um meio entre os corpos atuantes e, por isto, considera-se que ela ocorra instantaneamente.

${ }^{33}$ Arago se preocupava em verificar se o material com que era feito o fio e a sua geometria influenciavam no efeito. Esta preocupação era comum na época. Ørsted, por exemplo, considerava que a produção de calor e luz, por meio da corrente elétrica, em um fio metálico fino, era uma evidência de que calor e luz tinham uma profunda relação com a eletricidade [5, p. 116]. Ele imaginou que para manifestar os efeitos magnéticos, era necessário que o aparelho voltaico utilizado fosse suficientemente forte para incandescer um fio metálico [6, p. 274]. Posteriormente, verificou-se que fios com diâmetros maiores dão melhores resultados. Sabemos que, o coeficiente de resistividade é intrínseco ao material. Portanto, metais com o mesmo comprimento e mesma área de seção transversal, possuem resistências diferentes $(R=\rho l / A)$. Consequentemente, os fios metálicos ao serem ligados a uma mesma bateria terão diferentes intensidades de correntes e, portanto, agirão de maneiras ligeiramente distintas. Porém, isto é difícil notar. Para Ørsted, "a natureza do metal não afeta o efeito, mas apenas em sua quantidade. Fios de platina, ouro, prata, bronze, ferro, etc, são utilizados com igual sucesso" [6, p. 274].

${ }^{34}$ Ampère observou esta interação "ao dispor, em direções paralelas, dois fios condutores retilíneos unidos às extremidades de duas pilhas voltaicas: um fixo, e outro móvel, por um contrapeso, podendo aproximar-se ou se afastar conservando seu paralelismo com o primeiro" [7, p. 69]. Porém, ele afirma que é desnecessário utilizar duas pilhas diferentes. Basta que ambos condutores façam parte do mesmo circuito, para que com isto, a corrente elétrica tenha a mesma intensidade [7, p. 72]. Trabalho traduzido para a língua portuguesa em [8].

${ }^{35}$ De acordo com Ampère, "a ação mútua entre dois ímãs obedece à lei de interação entre correntes, ao conceber sobre a superfície e no interior dos ímãs, correntes elétricas em planos perpendiculares ao eixo destes ímãs" [7, p. 75].

${ }^{36}$ Ao ver que "a agulha imantada de uma bússola aponta constantemente em direção ao norte orientada pela Terra e que o experimento de Ørsted demonstra que esta mesma agulha sofre influência de uma corrente elétrica, de forma que o polo norte (austral) gira à esquerda do sentido da corrente, posicionando-a praticamente perpendicular ao fio, pode ser que, as diferentes rochas e minerais na crosta terrestre atuem como uma pilha, gerando correntes elétricas na terra responsáveis pelo alinhamento da bússola" [25, p. 27]. Nesta linha de raciocínio, Ampère imaginou "um homem deitado sobre a superfície da Terra de modo a ter a face voltada para a agulha, recebendo esta corrente, indo na direção dos pés a sua cabeça, concluindo disso que [esta corrente terrestre] ocorre de leste para oeste em direção perpendicular ao meridiano magnético" [26, p. 317] (ver Fig. 2). Ampère supôs que "as partículas da barra de um ímã atuam como os elementos de uma pilha que dirigem correntes ao redor da barra, produzindo correntes elétricas semelhante a um solenóide" [25, p. 27]. Portanto, Ampère reduziu o fenômeno da ação diretiva da Terra e da ação mútua entre dois ímãs, aos fenômenos eletrodinâmicos da interação entre correntes elétricas.

37 Ao fio enrolado em forma de hélice denominamos de solenóide. Esta agulha funciona como o núcleo do solenóide e se transforma em um ímã artificial enquanto houver a passagem da corrente elétrica pelo fio condutor (ver Fig. 3).

${ }^{38} \mathrm{O}$ método de Arago, como ele mesmo descreve, foi inicialmente dispor o fio em linha reta.

${ }^{39}$ Ver Fig. 4 
mas, somente após as comunicações entre os dois polos terem sido estabelecidas, a fim de que o efeito esperado não fosse atribuído à descarga elétrica, que se manifesta no mesmo instante em que o fio conjuntivo se conecta aos dois polos. 40 Durante o experimento, a parte deste fio na qual a agulha de aço estava colocada, foi mantida sempre perpendicular ao meridiano magnético, de modo que não houvesse nenhuma sensibilidade da ação do globo terrestre.

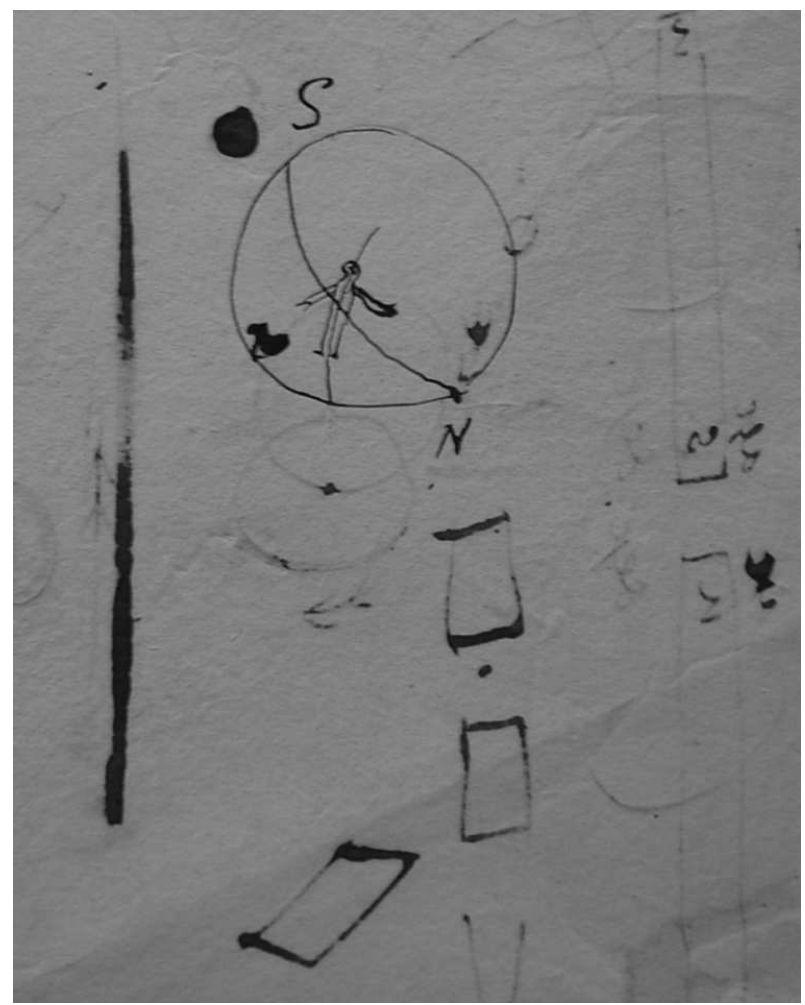

Figura 2 - Rascunho encontrado no manuscrito de Ampère. As letras $\mathbf{N}$ e $\mathbf{S}$ correspondem ao polo norte e sul geográfico, respectivamente. Fonte: A.M. Ampère, Archives de l'Académie des Science de Paris, carton 8, chemise 156. Figura também encontrada na Ref. [26, p. 317].

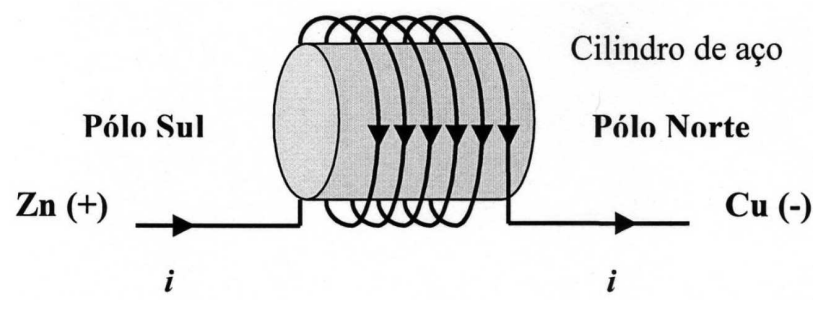

Figura 3 - Representação das espiras com núcleo de aço.

Ora, após alguns minutos de permanência na hélice, a agulha de aço recebeu uma forte dose de magnetismo; a posição dos polos norte e sul se encontrou, de fato, perfeitamente conforme ao resultado que o Sr. Ampère havia deduzido, de antemão, da direção dos elementos da hélice, ${ }^{41}$ e da hipótese de que a corrente elétrica percorre o fio conjuntivo indo da extremidade de zinco da pilha à extremidade do cobre. ${ }^{42}$

Portanto, parece provado, de acordo com estas experiências, que se um fio de aço é imantado por uma corrente galvânica que o percorre longitudinalmente, a posição dos polos não é determinada unicamente pela direção da corrente; e que as circunstâncias irrisórias e quase imperceptíveis, como por exemplo, um leve começo de imantação; uma ligeira irregularidade na

[p. 97]

forma ou na textura do fio podem alterar perfeitamente os resultados,, 43 enquanto que se a corrente galvânica circula ao redor do [cilindro de] aço, ao longo das espiras de uma hélice, se poderá sempre prever de antemão, aonde virão se colocar os polos norte e sul. $\underline{44}$

Refletindo, contudo, sobre os desacordos singulares que as experiências de imantação pelas descargas elétricas têm apresentado

\footnotetext{
${ }^{40}$ No instante em que ligamos o fio a uma forte bateria elétrica, há a produção de uma faísca. As faíscas elétricas eram características dos fenômenos eletrostáticos conhecidos. Arago tinha a preocupação de se certificar que a imantação da agulha era apenas devido ao fluxo contínuo das cargas elétricas, ou seja, um fenômeno eletrodinâmico e não eletrostático.

${ }^{41}$ Segundo Ampère, "os fenômenos magnéticos são unicamente produzidos pela eletricidade e não existe nenhuma diferença entre os dois polos de um ímã, que sua posição em relação às correntes que o compõe, de modo que o polo austral é aquele que se encontra à direita destas correntes e, o polo boreal é aquele que se encontra à esquerda" [7, p. 76].

${ }^{42}$ Para saber se a corrente existente no interior da pilha é a mesma que flui pelo fio, Ampère colocou uma bússola sobre a bateria e outra bússola abaixo e acima do fio conjuntivo. O eletrólito utilizado na pilha era a salmoura. Ele concluiu, dizendo que "a expressão direção da corrente elétrica dentro da pilha designará a direção que vai da extremidade onde o hidrogênio liberta-se na decomposição da água, para onde se obtém o oxigênio. Já a expressão direção da corrente elétrica no condutor, que estabelece a comunicação entre as duas extremidades da pilha, designará a direção que vai ao contrário, da extremidade onde se produz o oxigênio para onde se desenvolve o hidrogênio" [7, p. 64; 8, p. 95].

${ }^{43}$ Arago se refere aqui ao tipo de imantação em que a corrente elétrica percorre a agulha longitudinalmente, ressaltando que este tipo de imantação não apresentava resultados satisfatórios.

${ }^{44}$ Arago conclui, pelas experiências realizadas, que se a agulha de aço for introduzida no interior de um conjunto de espiras através das quais circula uma corrente elétrica, a agulha apresentará as características de um ímã comum, inclusive com polaridades.

${ }^{45}$ Muitos cientistas tentaram imantar uma agulha de aço com descargas elétricas provenientes de garrafas de Leiden que a atravessavam longitudinalmente. Para mais detalhes recomendamos a leitura da carta de Franklin a Peter Collinson [1].
} 
aos físicos que se ocuparam desta investigação, ${ }^{45}$ pareceu-me necessário submeter às provas mais decisivas os fenômenos das correntes helicoidais. O leitor irá julgar se nós atingimos este objetivo.

Imaginei primeiro, em formar, com um fio de cobre, duas hélices simétricas. ${ }^{46}$ Cada uma com cerca de cinco centímetros e, separadas por uma parte retilínea do mesmo fio; as espiras de uma das hélices giravam num sentido;

[p. 98]

[as espiras] da outra [hélice] em sentido contrário, mas com as inclinações paralelas (ver Fig. 4); os diâmetros eram iguais. Um cilindro de aço contido num pequeno tubo de vidro foi introduzido na primeira hélice; coloquei, em seguida, um cilindro perfeitamente semelhante ao precedente [na hélice vizinha], e garanti também [que não houvesse] qualquer contato elétrico colocando um isolante de vidrc ${ }^{47}$ na hélice vizinha; uma pequena extremidade de fio de cobre estabelecia uma comunicação constante entre esta última hélice e o polo positivo da pilha. A partir daí, para começar a experiência, era suficiente unir ao polo negativo, o fio que partia da extremidade da segunda hélice: ora, no instante em que esta comunicação era estabelecida, a eletricidade acumulada no polo positivo do instrumento se escoava pela parte direita do fio conjuntivo; atingia a primeira hélice, seguia gradualmente [por] todas as suas espiras, chegava à segunda hélice pelo fio reto que a separava da precedente, e após têla percorrido, retornava ao polo negativo. Os dois cilindros de aço se encontravam, portanto, submetidos um ao outro durante a experiência, pela ação de uma corrente galvânica de mesma intensidade. Esta corrente, densamente, movia-se em uma só direção mas se ela circulasse da esquerda para a direita, ao redor do primeiro cilindro, este mesmo movimento se executava da direita para a esquerda ao redor do segundo [cilindro]. Ora, em todas as experiências deste tipo que fizemos com o Sr. Ampère, utilizando uma pilha bastante forte que ele

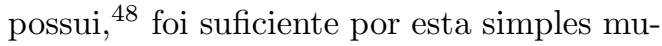
dança no sentido da qual a corrente circulava ao redor dos cilindros de aço, para dar lugar a uma inversão completa dos polos, de modo que os dois cilindros contidos nas duas hélices simétricas estavam, ao mesmo tempo, imantados em sentidos contrários. 49

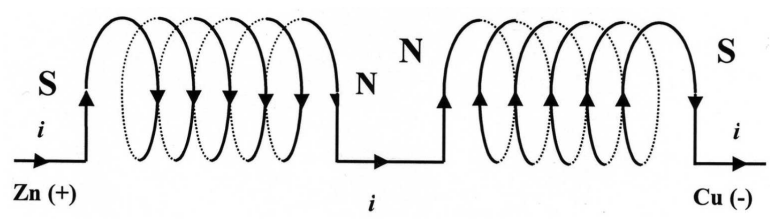

(a) Vista longitudinal
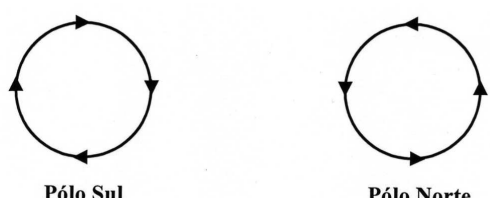

Figura 4 - Representação esquemática do experimento de François Arago. (a) Vista longitudinal; (b) Vista transversal - referente ao terminal de zinco $(+)$.

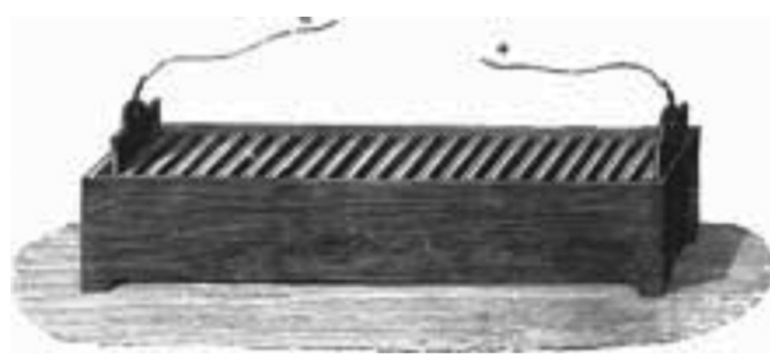

Figura 5 - Pilha horizontal de calha ou de tina Fonte: Ref. [8, p. 102].

\footnotetext{
46 [N. A.] Estas hélices simétricas são semelhantes àquelas que os botânicos designaram pelas palavras dextrorso [para direita] para uma, e sinistrorso [para a esquerda] para a outra. Os seus diâmetros são iguais; as espiras, que as compõe, têm as inclinações paralelas; mas elas não podem jamais serem sobrepostas, de qualquer maneira que se apresente uma à outra: de modo que, uma inversão qualquer não altere a espécie. A hélice (volta) dextrorso é aquela que a natureza nos oferece em um grande número de plantas trepadeiras, é também quase tão única, que se emprega nas artes. O cilindro de aço contido em uma hélice dextrorso adquire um polo austral (aquele que se dirige ao norte), do lado negativo, ou do cobre, do fio conjuntivo, enquanto que este mesmo polo se formará do lado positivo, ou do zinco, que se serve da hélice sinistrorso. Estes resultados estão de acordo com a teoria do Sr. Ampère.

${ }^{47} \mathrm{Na}$ época, era comum utilizar tubos de vidro ou fios de seda para evitar o contato elétrico entre os fios ou, como neste caso, entre o fio e o cilindro de aço.

${ }^{48}$ Provavelmente, Arago está se referindo à bateria de calha ou tina. Esta bateria teria "aproximadamente 60 cm de comprimento com uma seção reta de $20 \mathrm{~cm}$ por $20 \mathrm{~cm}$, sendo uma evolução da pilha de Volta" [8, p. 102]. Ao colocar uma pequena bússola sobre esta bateria e observar o deslocamento da agulha imantada quando flui uma corrente pelo circuito, Ampère obtém o sentido da corrente elétrica no interior da pilha, que vai do terminal negativo ao terminal positivo. No fio, a corrente flui em sentido contrário, ou seja, do terminal positivo ao terminal negativo [8, p. 102] (ver Fig. 5).

${ }^{49}$ Uma maneira de se inverter a polaridade de um solenóide é inverter o sentido da corrente que circula pelas espiras. Para isto, basta conectar o solenóide aos polos opostos da bateria elétrica.
} 
[p. 99]

Num outro ensaio, dobrei o fio de cobre em hélice, da direita para a esquerda sobre um comprimento de cinco centímetros. Seguidamente da esquerda para a direita, sobre um comprimento igual; depois, enfim, uma segunda vez, da direita para a esquerda: estas três hélices estavam separadas por porções retilíneas do mesmo fio.

Um único e mesmo cilindro de aço suficientemente longo, de mais de um milímetro de diâmetro, e envolvido por um tubo de vidro, foi colocado nas três hélices ao mesmo tempo. A corrente galvânica, ao percorrer as espiras destas diversas hélices, imanta as porções correspondentes do cilindro de aço, como se elas tivessem sido separadas umas das outras. Observei, com efeito, que em uma das extremidades se encontrava um polo norte; a cinco centímetros de distância, um polo sul; mais distante um segundo polo sul, seguido de um polo norte; por último, um terceiro polo norte, e a cinco centímetros daí, ou na outra extremidade do cilindro, um polo sul.50 Nós poderíamos, portanto, por este método, multiplicar à vontade estes polos intermediários que os físicos têm designado pelo nome de pontos consecutivos. 51

Eu devo observar, contudo, que em geral nestas experiências, a influência das hélices se exerce não somente sobre as porções do cilindro de aço contidas nelas, mas ainda, sobre as partes vizinhas; de modo que, por exemplo, se o intervalo compreendido entre as hélices consecutivas é pequeno, as porções do cilindro de aço, correspondentes a estes intervalos, serão imantadas como se o movimento de rotação imprimido ao fluido magnético, de acordo com a idéia do Sr. Ampère ${ }^{52}$ pela influência de uma hélice, continuasse para além das últimas espiras.

[p. 100]

Tendo procurado descobrir, enquanto escrevia a folha precedente, quais eram as circunstâncias que faziam variar a posição dos polos quando os fios de aço eram percorridos longitudinalmente por uma corrente galvânica, encontrei invariavelmente, que mesmo com uma pilha muito ativa, se o fio conjuntivo for perfeitamente reto, uma agulha de aço [sendo] colocada acima não recebe nenhum magnetismo. ${ }^{[53} \mathrm{A}$ agulha de costura a qual eu havia utilizado nas minhas primeiras experiências tinha evidentemente adquirido polos, porém, os efeitos dependentes da forma do fio conjuntivo não eram conhecidos. E para manter mais facilmente a agulha, tive que enrolar um pouco o fio ao redor ${ }^{54}$ das suas extremidades.

Vê-se que eu estava cauteloso nas experiências precedentes, para evitar que nenhuma descarga passasse do fio conjuntivo para a barra de aço sobre a qual operava. $[55$

Há, portanto, uma distinção essencial por estabelecer entre este modo de imantação e aquele que foi o objeto das investigações de Wilke, Franklin, Dalebard, Beccaria, VanSwinden e Van-Marum; ${ }^{\sqrt{6}}$ pois, neste último modo, a imantação era produzida pela passagem de uma forte faísca elétrica através da barra de aço ${ }^{57}$ Podia ser curioso, contudo, pesquisar se a faísca fornecida pela

\footnotetext{
${ }^{50}$ Outra forma de inverter os polos de um solenóide é enrolar as espiras em sentidos contrários. Por exemplo, se as espiras estiverem enroladas em sentido horário, elas devem ser enroladas em sentido anti-horário e vice-versa. Ao comentar o trabalho de Arago, Hachette afirma que "a espira pode girar da esquerda à direita da corrente, ou da direta à esquerda: No primeiro caso, o polo sul da agulha correspondendo ao polo norte do ímã terrestre, estaria o lado da placa de zinco do aparelho. No segundo caso, o polo norte da agulha é que estaria deste lado" [4, p. 42] (ver Fig. 4).

51 "O Sr. Arago, seguiu a teoria do Sr. Ampère, concebendo a idéia de que um fio conjuntivo torcido de maneira que duas espiras simétricas sejam colocadas uma após a outra. Estas espiras diferem entre si apenas na direção a qual seus pontos gerados giram ao redor dos seus eixos ocos: ao pôr uma agulha em cada eixo, as espiras e as agulhas se tornaram magnetizadas ao mesmo tempo, de modo que, seus polos de mesmo nome são sucessivos" [4, p. 43].

${ }^{52}$ Ampère imaginou um ímã como um conjunto de correntes elétricas em um plano perpendicular ao seu eixo, dirigidas ao longo de curvas fechadas concêntricas. Imitou esta montagem encurvando um fio em forma de uma espiral plana. Ao fazer passar uma corrente elétrica pela espiral, ela é fortemente atraída ou repelida pelos polos de um ímã. Ao substituir o ímã por outra espiral, obtêm-se as mesmas atrações e repulsões agindo à distância, dependendo do sentido no qual as espirais são enroladas e o sentido da corrente elétrica que circula pelas espirais [9, p. 207]; [10]; [11].

${ }^{53}$ A descarga elétrica não era a causa direta da imantação das agulhas. O que produzia a magnetização da agulha era o próprio campo magnético terrestre. A descarga elétrica apenas auxiliava o processo, como também isto ocorria ao aquecer agulhas em uma chama, ou ao martelá-las fortemente, mantendo-as na direção norte-sul [5, p. 92].

54 "O Sr. Arago magnetizou um pedaço de ferro e, posteriormente, um fio de aço, pondo-os em contato com, ou sob a influência de um fio conjuntivo. Um método simples de magnetização da agulha de aço pelo fio consiste em colocar a agulha no interior do fio conjuntivo que é torcido em forma de hélice" [4, p. 42].

${ }^{55}$ Como vimos, Arago isolava o fio do cilindro de aço, por meio de tubos de vidro.

${ }^{56}$ Cientistas que pesquisaram sobre os fenômenos da magnetização de agulhas por meio da eletricidade estática.

${ }^{57}$ Método de magnetização em que a corrente elétrica, proveniente de garrafas de Leiden, percorre a agulha longitudinalmente.
} 
pilha não se comporta como aquela que se escapa de uma máquina eletrostática. Ora, aprendi com o Sr. Boisgiraud, instrutor de física na escola militar Saint-Cyr, que fez esta experiência com sucesso. Ele suspeitava que operando assim, a

[p. 101]

força magnética somente se tornava um pouco mais sensível, tanto que, as duas porções de fio destinadas a conectar a agulha aos polos de cobre e zinco são de aço, e elas formam como que duas espécies de armaduras. O Sr. Boisgiraud promete, a este respeito, novas experiências, as quais nós nos apressaremos em divulgar aos leitores dos Anais. 58

O fio conjuntivo de cobre é dotado, como se tem visto, de uma virtude magnética muito intensa, quando ele se comunica aos dois polos da pilha. Ele chegou, mais uma vez, a apresentar ainda, vestígios desta propriedade, cerca de instantes após a comunicação entre os dois polos ter sido totalmente interrompida. Mas este fenômeno é muito fugaz, e eu não pude reproduzi-lo à vontade. O Sr. Boisgiraud não foi mais feliz que eu, embora, num caso, o cilindro de platina que ele utilizava se conservou com bastante força, após ter sido completamente desconectado da pilha, para suportar uma pequena agulha de costura. $[59$

As experiências do Sr. Ørsted, parecemme que podem ser repetidas numa circunstância que acrescentaria ainda [mais] ao interesse que elas devem inspirar, fazendonos dar um passo a mais em direção a explicação do fenômeno, até agora, [tão] incompreensível, das auroras boreais. Exis- te, na Instituição Real de Londres, uma pilha voltaica, composta de 2000 placas duplas de quatro polegadas ${ }^{60}$ quadradas. Servindo-se deste potente aparelho, o Senhor Humphry Davy ${ }^{61}$ reconheceu que se produz uma descarga elétrica entre duas pontas de carvão adaptadas

[p. 102]

às extremidades dos condutores positivos e negativos, mesmo que estas pontas estejam ainda distantes uma da outra 1/30 ou $1 / 40$ de polegada. O primeiro efeito da descarga é avermelhar os carvões. Ora, tão logo a incandescência é estabelecida, as pontas podem ser gradualmente aproximadas, até quatro polegadas, sem que com isto, a luz intermediária se rompa. Esta luz é extremamente viva, e mais larga no seu meio, do que nas suas extremidades: ela tem a forma de um arco ${ }^{62}$ A experiência terá melhor resultado quanto mais o ar estiver rarefeito ${ }^{63}$ Sob uma pressão de um quarto de polegada, a descarga de uma ponta de carvão à outra começava a uma distância de meia polegada. Afastando gradualmente os carvões, o Senhor Humphry Davy obteve uma chama púrpura contínua, e que tinha até sete polegadas de comprimento 64

É, sem dúvida, muito natural supor que esta corrente elétrica agirá sobre a agulha imantada da mesma maneira que se movesse ao longo de um fio conjuntivo metálico. No entanto, a experiência me parece merecer ser recomendada aos físicos que têm às suas disposições, pilhas voltaicas de uma grande força, sobretudo devido às vistas que se pode fazer nascer relativamente às auroras boreais. Não seria, aliás, independentemente de toda aplicação imediata,

${ }^{58}$ Anais da Academia Francesa de Ciências.

59 "O Sr. Boisgiraud, um físico repleto de sagacidade, leu na sessão de 9 de outubro de 1820, algumas experiências interessantes sobre a ação mútua entre condutores e ímãs. Em uma destas experiências ele não deixa dúvida sobre um ponto importante da teoria, ao provar que esta ação ocorre entre o fio condutor e todas as seções transversais perpendiculares à linha que une os dois polos do pequeno ímã sobre o qual ele age, sem se desenvolver com uma maior energia sobre os polos de ímã, como se observa na ação que os diversos pontos do comprimento de uma barra imantada exercem sobre a pequena agulha" [9, p. 218].

${ }^{60}$ Uma polegada equivale a aproximadamente $2,54 \mathrm{~cm}$.

${ }^{61}$ Humphry Davy (1778-1829).

${ }^{62}$ Davy usando uma pilha voltaica grande, da Royal Instituto de Londres, em 1809, demonstrou a descarga de arco com eletrodos de carvão. Entretanto, a data exata e as circunstâncias de suas primeiras demonstrações ainda são objetos de pesquisas. Posteriormente, usando uma bateria de 2000 pares de placas da Instituição de Londres, em 1821, Davy encontrou que campos magnéticos afetam arcos de plasma [28, p. 1068].

${ }^{63}$ Aqui existem alguns indícios das primeiras idéias relacionadas a lâmpada elétrica incandescente.

${ }^{64}$ É interessante notar como a faísca elétrica despertava interesse dos cientistas do final do século XVIII e início do século XIX. Franklin em carta a Peter Collinson, escreve: "Eu tenho ouvido, que alguns de seus eletricistas europeus não têm sido capazes de incendiar pólvora pela chama elétrica. Nós fazemos aqui desta maneira: um pequeno cartucho é cheio com pólvora seca, fortemente socada, a fim de quebrar alguns de seus grãos. Dois fios pontiagudos são então introduzidos em cada uma das extremidades. As pontas ficam próximas uma da outra na metade do cartucho, ainda à distância de meia polegada. Então, o cartucho é colocado em um circuito, quando quatro jarras [garrafas de Leiden] são descarregadas, a chama elétrica salta da ponta de um fio à extremidade do outro [fio], dentro do cartucho e entre a pólvora. O fogo e a explosão da pólvora acontecem no instante do estampido da descarga [elétrica]" $[1$, p. 291]. 
um fenômeno digno de observação, que a produção no vácuo, ou com ar muito rarefeito, de uma chama que, agindo sobre a agulha imantada, por sua vez, fosse atraída ou afastada pelos polos do ímã?
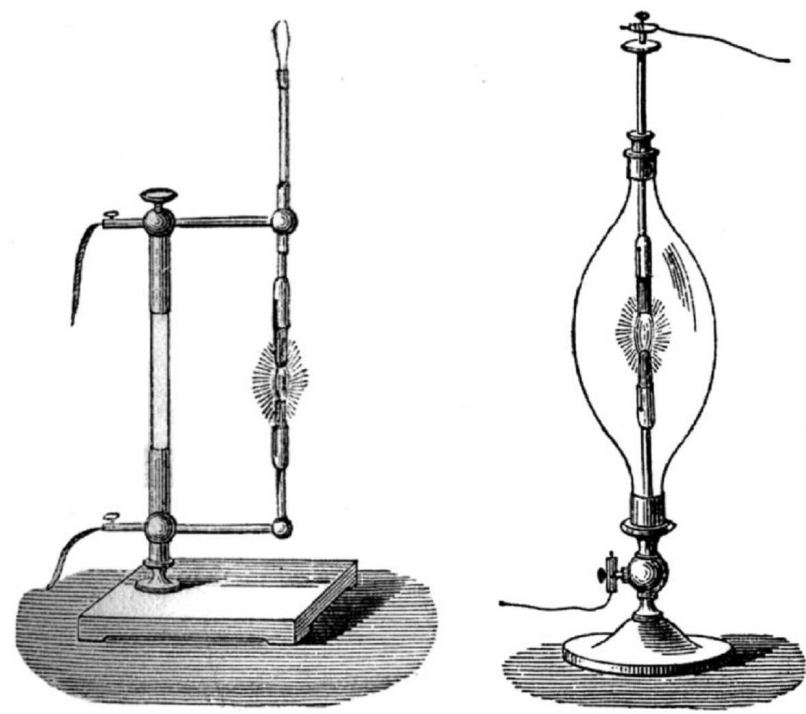

Figura 6 - Lâmpadas de arco com eletrodos de carvão, no ar e em tubo de vidro a vácuo, usadas por Davy. Fonte: Ref. [28, p. 1068].

\section{Agradecimentos}

Os autores agradecem ao Prof. Dr. André Koch Torres de Assis pela revisão do artigo. Agradecem também a Sérgio Luiz Bragatto Boss e a João Paulo Martins de Castro Chaib pelas sugestões apresentadas ao trabalho.

\section{Referências}

[1] B. Franklin, Philosophical Transactions 47, 289 (1751). Disponível em http://www.jstor.org Acessado em $22 /$ nov $/ 2007$.

[2] G. Magalhães, in: Atas do $10^{\circ}$ Seminário Nacional de História da Ciência e Tecnologia, Belo Horizonte, 2005. Disponível em CDROM.

[3] R.A. Martins, in: Hans Christian Ørsted and Romatica Legacy in Science: Ideas, Disciplines, Practices, edited by R.M. Brain, R.S. Cohen and O. Knudsen. Boston Studies in Philosophy of Science 241, 339 (2007). Disponível em http://www.ifi.unicamp.br/ $\sim$ ghtc/ram-pub.htm Acessado em 26/mar/2008.

[4] J.N.P. Hachette, Philosophical Magazine 57, 40 (1821). Disponível em http://www.ampere.cnrs.fr. Acessado em $22 /$ nov $/ 2007$.
[5] R.A. Martins, Caderno de História e Filosofia da Ciência 10, 89 (1986). Disponível em http://www. ifi.unicamp.br/ ghtc/ram-pub.htm Acessado em $22 /$ nov/2007.

[6] H.C. Ørsted, Annals of Philosophy 16, 273 (1820). Disponível em http://www. ampere.cnrs.fr. Acessado em $26 / \mathrm{mar} / 2008$.

[7] A.M. Ampère, Annales de Chimie et de Physique 15, 59 (1820). Disponível em http://www.ampere.cnrs. fr. Acessado em 22/nov/2007.

[8] J.P.M.C. Chaib e A.K.T. Assis, Revista da SBHC 5, 85 (2007).

[9] A.M. Ampère, Annales de Chimie et de Physique 15, 170 (1820). Disponível em http://www . ampere.cnrs . fr. Acessado em 22/nov/2007.

[10] M.P. Souza Filho, J.P.M.C. Chaib, J.J. Caluzi e A.K.T. Assis, Revista Brasileira de Ensino de Física 29, 605 (2007).

[11] A.K.T. Assis, M.P. Souza Filho, J.J. Caluzi and J.P.M.C. Chaib, in: Hands-on Science - Development, Diversity and Inclusion in Science Educations (Ponta Delgada, Portugual, 2007).

[12] J.B. Biot and F. Savart, Annales de Chimie et de Physique 15, 222 (1820). Disponível em http://www. ampere.cnrs.fr Acessado em 22/nov/2007.

[13] A.K.T. Assis e J.P.M.C. Chaib, Cadernos de História e Filosofia da Ciência 16, 303 (2006).

[14] D.F.J. Arago, Annales de Chimie et de Physique 15, 93 (1820). Disponível em http://www.ampere.cnrs.fr Acessado em 22/nov/2007.

[15] D.F.J Arago and A.J. Fresnel, in: A Source Book in Physics, edited by W.F. Magie (Mc Graw-Hill, New York and London, 1935), $1^{\mathrm{a}}$ ed., p. 425-434.

[16] J.G. Neiesten and O.T. Tan, IEEE Translations on Education 32, 160 (1989).

[17] M.P. Oliveira, Revista da SBHC 13, 45 (1995).

[18] D.F.J. Arago, Meteorological Essays: by François Arago (Longman, Brown, Green and Longmans, London, 1855).

[19] D.F.J. Arago, in: A Source Book in Physics, editeb by W.F. Magie (Mc Graw-Hill Book Company, Inc., New York and London, 1935), $1^{\mathrm{a}}$ ed., p. 443-444.

[20] W. Beton (ed.), Encyclopadia Brittannica (Encyclopedia Britannica, Incorporated, Illinois, 1969), v. 2, p. 204.

[21] M. Faraday, in: Electro-magnetism (Arno Press, New York, 1981), v.2, p. 1-35.

[22] R. Ferraro and D.M. Sforza, European Journal of Physics 26, 195 (2005).

[23] M.P. Oliveira, Caderno Catarinense de Ensino de Física 10, 157 (1993).

\footnotetext{
${ }^{65}$ Ora, se a faísca que salta entre os carvões é de mesma natureza que a corrente elétrica, o Sr. Ørsted demonstrou que a corrente age sobre a agulha imantada, então, pelo princípio da ação e reação, a agulha imantada deveria reagir sobre o fio condutor. O próprio Ørsted construiu um aparelho galvânico móvel, colocando-o próximo a um potente ímã para ver a reciprocidade entre esta ação mútua. "Eu fiz uso de diferentes variações de simples aparelho galvânico para examinar o movimento impresso sobre ele [o fio], pelo ímã" [16, p. 423]. Para Arago, como esta força é pequena e o fio deveria ser extremamente móvel, ele imaginou que pudesse ser visível verificar esta reação, através da faísca elétrica que salta entre os dois carvões.
} 
[24] A. Volta, Philosophical Transactions 90, 403 (1800). Disponível em http://www. ampere.cnrs.fr. Acessado em $22 /$ nov/2007.

[25] R.A.R. Tricker, Early Electrodynamics - The First Law of Circulation (Pergamon Press, Oxford, 1965).

[26] J.P.M.C. Chaib e A.K.T. Assis, in: I Simpósio de Pesquisa em Ensino e História em Ciências da
Terra, Campinas, 2007. Disponível em http://www. ige.unicamp.br/simposioensino/artigos/008.pdf .

[27] H.C. Ørsted, in: Selected Scientific Works of Hans Cristian Ørsted (Princeton University Press, New Jersey, 1998), p. 421-424.

[28] A. Anders, IEEE Translations on Plasma Science 31, 1060 (2003). 